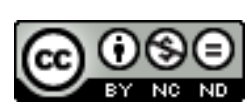

Revista Pax Domini é licenciada sob uma Licença Creative Commons.

\title{
O LUGAR DO SAGRADO NA CULTURA SATERÉ MAWÉ
}

Geneci Behling Bett*

Raimunda dos Santos Motta**

\begin{abstract}
Resumo
O presente artigo tem como objetivo descrever e apresentar o fenômeno religioso de caráter universal, constituído do aspecto inerente ao ser humano, através do conhecimento da manifestação do sagrado na cultura da Etnia Sateré Mawe através do ritual de passagem vivenciado pelos meninos que assinala a passagem da criança para a idade adulta concretizado no mito da formiga Tucundeira. O trabalho foi desenvolvido com a pesquisa bibliográfica trazendo uma contribuição para a compreensão da importância e do significado deste ritual para a cultura da Etnia Sateré Mawe na Amazônia.
\end{abstract}

Palavras-chave: sagrado, mito, ritual da Tucandera, Sateré-Mawé

\begin{abstract}
The present article aims to describe and present the religious phenomenon of a universal character, constituted by the inherent aspect of the human being, through the knowledge of the manifestation of the sacred in the Satere Mawe ethnic culture through the ritual of passage experienced by the children that marks the passage of Child to adulthood concretized in the Tucundeira ant myth. The work was developed with the bibliographical research bringing a contribution to the understanding of the importance and meaning of this ritual for the Sateré Mawe Ethnic culture in the Amazon.
\end{abstract}

Keywords: Sacred, myth, ritual of the Tucandera, Sateré-Mawé

\footnotetext{
* Geneci Behling Bett - Mestre em Teologia pela EST/RS; Doutoranda do Curso de Doutorado da EST/RS. Profa Universitária da Faculdade Boas Novas de Manaus - AM.

** Raimunda dos Santos Mota - Mestre em Educação Especial pela Universidade do Minho - Braga/PT. Doutoranda da Curso de Doutorado da EST/RS. Coordenadora e Prof ${ }^{\mathrm{a}}$ do Curso de Pedagogia da Faculdade Boas Novas de Manaus - AM.
} 


\section{INTRODUÇÃO}

O fenômeno religioso é um fenômeno de caráter universal, pois todas as sociedades humanas manifestam alguma expressão religiosa constituindo-se um aspecto inerente ao ser humano. As religiões influenciam a cultura que influencia as religiões.

As religiões influenciam a cultura que influencia as religiões. Sendo importante conhecer a diversidade das manifestações do sagrado para compreender o comportamento religioso dos cidadãos numa sociedade plural e diversa, como são as comunidades indígenas. Diante do conhecimento, é possível promover a superação dos preconceitos, construir relações de diálogo, alteridade e respeito às diferenças.

A grande maioria das culturas indígenas são organizadas, a partir dos princípios de solidariedade, partilha e generosidade entre os membros da tribo. Essas atitudes éticas abrangem a todos e em muitos casos até mesmo os inimigos. Com certeza, esse é um exemplo a ser aprendido e seguido pela nossa sociedade marcada pelo individualismo, ganância, competição e consumismo desenfreado.

Os índios querem continuar sendo índios e têm esse direito assegurado na Constituição do nosso país. "São reconhecidos aos índios sua organização social, costumes, línguas, crenças e tradições, e os direitos originários sobre as terras que tradicionalmente ocupam, competindo à União demarcá-las, proteger e fazer respeitar todos os seus bens." (Constituição Federal - Art.231) ${ }^{1}$.

Quando se fala em espiritualidade e religiosidade indígena é importante entender que suas religiões, marcadas pela praticidade, estão impregnadas de sentido do sagrado, tudo está ligado. O ser humano nasce puro e pode viver em plena comunhão com o Grande Espírito sem medo da condenação eterna ou do pecado original. Não há necessidade de religar-se, pois já está ligado à Mãe Vida, à Natureza, de modo que tudo o que nos foi dado pelo Grande Espírito é sagrado, e é dever de cada membro da comunidade viver em harmonia com toda a vida².

Conhecer as expressões religiosas dos povos indígenas permite compreender melhor a sua cultura e superar o preconceito que muitos ainda têm em relação ao indígena e seu modo de vida, pois, possuem formas diversificadas de expressão do sagrado, utilizando-se

\footnotetext{
${ }^{1}$ http://www.planalto.gov.br/ccivil_03/constituicao/constituicaocompilado.htm acessado dia 20.02.2017.

2 http://www.gper.com.br/noticias/e16497de60b8cdb335b018803d3040fd.pdf acessado dia 28.02.2017.
}

Revista Pax Domini | Faculdade Boas Novas | v. 2 | p. 111 - 121 | mar. 2017 
de rituais que estão impregnados de significados e valores. Este estudo apresenta o rituais da formiga tucandeira, que caracteriza a cultura da etnia Sateré-Mawé do Estado do Amazonas.

\section{SAGRADO}

O homem das sociedades arcaicas têm a tendência para viver o mais possível no sagrado ou muito perto dos objetos consagrados, pois para os "primitivos", como para o homem de todas as sociedades pré-modernas, o sagrado equivale ao poder e, em última análise, à realidade por excelência. A potência sagrada quer dizer ao mesmo tempo realidade, perenidade e eficácia maneira o homem religioso se esforça por manter se o máximo de tempo possível num universo sagrado. Eliade afirma :

O desejo do homem de viver no sagrado equivale, de fato, ao seu desejo de se situar na realidade objetiva, de não se deixar paralisar pela relatividade sem fim das experiências puramente subjetivas, de viver em um mundo real e eficiente - e não numa ilusão ${ }^{3}$.

Ao longo da história, o homem religioso valorizou determinados espaços mais do que os outros passando a chama-lo de sagrado, espaço em que o culto a essa sacralidade é feito por meio do local, dos mitos, símbolos, ritos e doutrinas que diferencia o homem religioso do homem não religioso. A experiência do sagrado torna possível a fundação ou criação do mundo.

O sagrado é aquilo que se distingue totalmente do comum, é algo que se revela completamente diferente do mundo cotidiano. $O$ que se revela como sagrado não pertence ao mundo comum, é algo que transcende este mundo, que é incrivelmente superior a ele. O desejo do homem de viver no sagrado equivale, de fato, ao seu desejo de se situar na realidade objetiva, de não se deixar paralisar pela relatividade sem fim das experiências puramente subjetivas, de viver em um mundo real e eficiente - e não numa ilusão4. Para Guimarães

\footnotetext{
${ }^{3}$ ELIADE, M. O sagrado e o profano: a essência das religiões. São Paulo: Martins Fontes, 2001, p.32.

${ }^{4}$ Ibidem, p.32.
}

Revista Pax Domini | Faculdade Boas Novas | v. 2 | p. 111 - 121 | mar. 2017 
[...] nos seus sonhos, devaneios, fantasmas, etc., a presença de estruturas "religiosas", afirma que elas não chegam a constituir experiências religiosas propriamente ditas, uma vez que não são vividas pelo homem total, e não se acham integradas numa religião como visão totalizadora do real. Ele chama essas "mitologias privadas" presentes na vida psíquica do homem moderno "pseudoreligiões","mitologias degradadas" (terminologia que traduz um esvaziamento ou perda de uma significação originária, uma relação,

portanto, descendente entre o que seria "mais elevado" e o que se mostra num "nível inferior", e indica aquele como a chave hermenêutica para a interpretação deste ultimo 5 .

\section{O MITO E O RITO}

Mito como História sagrada: para Eliade ${ }^{6}$, mito é história sagrada, porque remete a algo que existe de fato; é uma narrativa que conta o surgimento de uma categoria, de uma realidade, de um acontecimento. Mito, portanto, é uma linguagem apropriada para a religião. Isso não significa que a religião, tampouco o mito, conte uma história falsa, mas que ambos traduzem numa linguagem plástica (isto é, em descrições e narrações) uma realidade que transcende o senso comum e a racionalidade humana e que, portanto, não cabe em meros conceitos analíticos.

Os ritos, rituais e as cerimônias passam a ser elementos estratégicos a serviço da construção e consolidação das imagens das organizações, apoiadas na credibilidade e aceitação social das ações e realizações desenvolvidas. Segalen ${ }^{7}$ se preocupa com o que considera uma difusão abusiva dos termos rito e ritual, e os define como:

[...] um conjunto de atos formalizados, expressivos, portadores de uma dimensão simbólica. O rito é caracterizado por uma configuração espaço-temporal específica, pelo recurso a uma série de objetos, por sistemas de linguagem e comportamentos específicos e por signos emblemáticos cujo sentido codificado constitui um dos bens comuns do grupo. O uso do ritual é paralelo ao aparecimento da humanidade.

O rito fundamenta toda a realidade, define a organização da vida social e é fonte de memória e conhecimento. Há rituais para celebrar o fim das estações da chuva ou seca, outros para comemorar a chegada das colheitas; há rituais de casamento e vitórias em

\footnotetext{
${ }^{5}$ GUIMARÃES, Andre Eduardo. O sagrado e a historia: fenômeno religioso da historia a luz do antihistoricismo de Mircea Eliade. Porto Alegre: EDIPUCRS, 2000,p.445.

${ }^{6}$ ELIADE, 2001, p.35.

${ }^{7}$ SEGALEN, Martine. Ritos e Rituais Contemporâneos. Rio de Janeiro: FGV, 2002, p. 31.
}

Revista Pax Domini | Faculdade Boas Novas | v. 2 | p. 111 - 121 | mar. 2017 
guerras com outras tribos. Revestem-se de grande importância para as famílias os rituais de iniciação ou passagem para a vida adulta dos jovens e também o nascimento de crianças. Os rituais estão ligados aos mitos. O ritual e o mito atualizam o passado e ajudam a modificar e compreender o presente. Os ritos de passagem podem representar:

a) Mudança de um estado social para outro;

b) Processo de esvaziamento: o candidato perde o que já tinha, mas ainda não tem o que terá;

c) Ritos de passagem de adolescência.

\title{
4 A CULTURA SATERE MAWE
}

Segundo relatos dos velhos Sateré-Mawé, seus ancestrais habitavam em tempos imemoriais o vasto território entre os rios Madeira e Tapajós, delimitado ao norte pelas ilhas Tupinambaranas, no rio Amazonas e, ao sul, pelas cabeceiras do Tapajós. Os Sateré-Mawé referem-se ao seu lugar de origem como sendo o Nusoken, lugar da morada de seus heróis míticos. Eles localizam-no na margem esquerda do Tapajós, numa região de floresta densa e pedregosa, "lá onde as pedras falam". Nunes Pereira ${ }^{9}$, que viveu com esse povo na década de 1950, conta que

\begin{abstract}
"os lagos e rios piscosíssimos que irrigam as terras em que viveram outrora os Maués e, bem assim, as florestas e campinaranas ricas em caças de toda espécie, deveriam constituir, numa época mais remota, uma paisagem magnífica para as atividades desse povo. À representação panteísta do Noçoquem, - sítio onde se encontravam todas as plantas e animais úteis aos Maués, segundo a Lenda do Guaraná, deveria corresponder, outrora, o território por eles ocupado".
\end{abstract}

Os Sateré-Mawé tiveram seu primeiro contato com os brancos na época de atuação da Companhia de Jesus, quando os jesuítas fundaram a Missão de Tupinambaranas, em 1669. Segundo Bettendorf ${ }^{10}$,

\footnotetext{
8 http://www.gper.com.br/noticias/e16497de60b8cdb335b018803d3040fd.pdf acessado em 10.02.2017.

${ }^{9}$ PEREIRA, Nunes. Ensaio de etnologia amazônica. $2^{\underline{a}}$ ed. Manaus: Imprensa Pública, 1942, p. 5.

10 BETENDORF, João Felipe. Crônica da missão dos padres da Companhia de Jesus no estado do Maranhão. Rev. do IHG, Rio de Janeiro : IHG, n. 1, 1910, p.36.
}

Revista Pax Domini | Faculdade Boas Novas | v. 2 | p. 111 - 121 | mar. 2017 
"Em 1698 os Andirá acolheram o Padre João Valladão como missionário. É impossível localizar os Maraguá precisamente, mas eles viviam num lago, entre os rios Andirá e Abacaxi, provavelmente no baixo Maués-Açu, que se espraia para formar uma espécie de lago. Eles tinham três vilas, uma próxima da outra".

A partir do contato com os brancos, e mesmo antes disso, devido às guerras com os Munduruku ${ }^{11}$ e Parintintim ${ }^{12}$, o território ancestral dos Sateré-Mawé foi sensivelmente reduzido. Em 1835 eclodiu a Cabanagem na Amazônia, principal insurreição nativista do Brasil. Os Munduruku e Mawé (dos rios Tapajós e Madeira) e os Mura (do rio Madeira), bem como grupos indígenas do rio Negro, aderiram aos cabanos e só se renderam em 1839. Epidemias e perseguição aos grupos indígenas que com eles combatiam, deslocaram esses grupos dos seus territórios tradicionais, reduzindo-os ${ }^{13}$.

Eles são, tradicionalmente índios da floresta, do centro, como eles próprios falam. Até o começo do século XX escolhiam lugares preferencialmente nas regiões centrais da mata, próximas às nascentes dos rios, para implantarem suas aldeias e sítios. Nessas regiões, a caça é abundante; encontra-se em profusão os filhos de guaraná (Paullinia Sorbilis $\left.{ }^{14}\right)$. A primeira descrição do guaraná e de sua importância para os Sateré-Mawé é de 1669, ano que coincide com o primeiro contato do grupo com os brancos. Segundo o padre João Felipe Betendorf ${ }^{15}$ :

\begin{abstract}
"tem os Andirazes em seus matos uma frutinha que chamam guaraná, a qual secam e depois pisam, fazendo dela umas bolas, que estimam como os brancos o seu ouro, e desfeitas com uma pedrinha, com que as vão roçando, e em uma cuia de água bebida, dá tão grandes forças, que indo os índios à caça, um dia até o outro não têm fome, além do que faz urinar, tira febres e dores de cabeça e cãibras".
\end{abstract}

\footnotetext{
${ }^{11}$ Povo de tradição guerreira, os Munduruku dominavam culturalmente a região do Vale do Tapajós, que nos primeiros tempos de contato e durante o século XIX era conhecida como Mundurukânia. Hoje, suas guerras contemporâneas estão voltadas à garantir a integridade de seu território, ameaçado pelas pressões das atividades ilegais dos garimpos de ouro, pelos projetos hidrelétricos e a construção de uma grande hidrovia no Tapajós.

${ }^{12}$ Os Parintintin integram o conjunto de 'pequenos grupos que se autodesignam Kagwahiva, mas que hoje são conhecidos por nomes separados, muitos deles dados por grupos inimigos. Os Parintintin, nome possivelmente dado pelos Munduruku, são os que habitam mais ao norte. Entre as singularidades dos Kagwahiva em relação aos outros Tupi-Guaranis, destaca-se a organização social em metades exogâmicas com nomes de pássaros.

${ }^{13} \mathrm{https}$ ://pib.socioambiental.org/pt/povo/satere-mawe/print acessado em 05.03.2017.

${ }^{14}$ Paullinia cupana Kunth, comumente chamado guaraná, guaranazeiro e uaraná, é um cipó originário da Amazônia. É encontrado no Brasil, Peru, Colômbia e Venezuela, sendo cultivado principalmente no município de Maués, no estado do Amazonas, e na Bahia. Pertence a família Sapindaceae.

${ }^{15}$ BETENDORF,1910, p.41.
}

Revista Pax Domini | Faculdade Boas Novas | v. 2 | p. 111 - 121 | mar. 2017 
Além do guaraná, outro elemento importante da identidade Sateré-Mawé é o Ritual da Tucandeira. Vivenciado pelos meninos, esse rito assinala a passagem da criança ao adulto. Consiste na experiência de se colocar a mão na luva de palha trançada, onde estão aprisionadas as formigas tucandeiras com os ferrões voltados para a face interna do artefato de modo que o iniciante sofra dolorosas ferroadas enquanto são realizados cânticos e danças. Importante evento formador da identidade sateré-mawé.

Contudo, Kapfhammer ${ }^{16}$ entende que o ritual é objeto de reconstruções que ocorrem tanto no rito quanto no significado da mitopráxis ${ }^{17}$. Tais mudanças, construídas no processo histórico do contato dos Sateré-Mawé com grupos da sociedade envolvente, decorrem de discussões e críticas internas relativas aos diferentes segmentos sociais desse povo com clãs diferenciados que estabelecem as estratégias sociopolíticas de sobrevivência nos espaços fora do território ancestral, nos centros urbanos. Tal processo gera disjunções entre os segmentos, operando-se uma transformação/criação/recriação da mitopráxis de cada grupo.

O ritual da Tucandeira na tribo sateré-mawé. Este evento é realizado como forma de iniciação masculina. O índio sateré-mawé, para provar sua força, coragem e resistência à dor, deve se deixar ferrar no mínimo 20 vezes, colocando as mãos dentro da luva da tucandeira. As tucandeiras são formigas grandes com ferrão muito dolorido que, na véspera do ritual, são capturadas vivas e conservadas num bambu. Os meninos levantam cedo para terem seus braços pintados com o preto do jenipapo feito por suas mães; em seguida, com um dente de paca, elas começam a riscar a pele dos meninos até sangrar. A luva é feita de palha pelos padrinhos, que são os tios maternos.

No dia da cerimônia, pela manhã, são colocadas em uma bacia com tintura de folha de cajueiro, que tem efeito anestesiante, e meio adormecidas, as tucandeiras são postas na luva, com a cabeça para fora e o ferrão para dentro, na parte interna da luva. Não há um período certo para a realização do ritual: é organizado conforme a vontade de quem deseja ser iniciado. O evento envolve cantos e danças onde as mulheres, sobretudo as

\footnotetext{
${ }^{16}$ KAPFHAMMER, Wolfgang De 'sateré puro' (Sateré sese) ao 'novo sateré' (Sateré pakup): mitopráxis no movimento evangélico entre os Sateré-mawé. In: Wright, Robin (Org.). Transformando os deuses: igrejas evangélicas, pentecostais e neopentecostais entre os povos indígenas no Brasil. Campinas: Editora da Unicamp, 2004,p.101-104.

${ }^{17}$ Mitopráxis é a transformação/criação/recriação do mito na cultura.
}

Revista Pax Domini | Faculdade Boas Novas | v. 2 | p. 111 - 121 | mar. 2017 
solteiras, que buscam maridos fortes e corajosos, podem entrar na fila da dança junto com outros homens.

O ritual da tucandeira encarna um aprendizado repassado de geração a geração por meio da tradição oral. Este conjunto de patrimônios imateriais herdado dos ascendentes Sateré guardam acontecimentos históricos que marcaram a cosmovisão étnica. O seja, a dança, o cântico da tucandeira, a luva tecida com palha da floresta, o menino trazido ao ritual pelas mãos de mulheres e tantos outros elementos simbólicos presentes neste ritual de passagem, remetem à celebração de um feito mitológico da memória ancestral da etnia.

O principal embate do jovem Sateré-Mawé é contra o seu próprio ego. Enquanto convive com os outros seres ancestrais e com os espíritos da natureza no mundo transcendental, confronta consigo mesmo, com a sua visão pueril do mundo da vida, com o seu ser limitado. Durante o tempo em que o menino dança com as mãos nas luvas, lutando no universo metafísico, ele se depara com a sua real condição.

Quando celebram, ou executam o rito, recordam o tempo mítico e vivificam o tecido cultural. Pinheiro ${ }^{18}$ assinala que "os mitos trazem oculto em suas células um código minemônico ${ }^{19}$ ancestral capaz de revelar ao humano a sua biologia de origem, mesmo quando essa memória ancestral é obliterada pela cultura".

Neste âmbito metafísico, o jovem reúne os conhecimentos que aprendeu, ou seja, todos os mistérios que ele conheceu na preparação do rito, agora são confrontados no mundo transcendental. Esses conhecimentos vão fazer parte de sua prática de vida havendo, pois, um casamento entre mito e significado ${ }^{20}$.

Para Eliade ${ }^{21}$, só é possível chegamos às raízes espirituais do sagrado se rompermos com a miopia ocidental. É nesta esfera espiritual que o mito ocupa lugar de primazia, ou seja, por meio da mitologia se obtêm a mensagem sacra da comunidade étnica. No conjunto da cerimônia ritualística de passagem do Sateré-Mawé há o gérmen da metafísica clânica, a manifestação da sua ontologia em que o jovem se entrelaça ao simbólico-religioso. Este é, por excelência, o elemento diacrítico da etnia. Aqui há o tempo mágico do mito, a dança desenfreada e sem nenhuma coreografia fixa, sem normas,

${ }^{18}$ PINHEIRO, Harold Sá Peixoto. Mitopóetica dos muyraquitãs, parandubas e moronguetás: ensaio de etonopoesia amazônica. São Paulo: Tese de Doutorado, 2013.p. 48.

${ }^{19}$ Minemônico, é um auxiliar de memória, para memorizar listas ou fórmulas.

${ }^{20}$ LÉVI- STRAUSS, Claude. Mito y significado. Madrid: Alianza, 1990.

${ }^{21}$ ELIADE, Mircea. História das crenças e ideias religiosas. Rio de Janeiro: Zahar. t.1. v.1 1985.

Revista Pax Domini | Faculdade Boas Novas | v. 2 | p. 111 - 121 | mar. 2017 
ausências de limites, num instante divino em que o homem se une com a totalidade, com a mãe, a Gaia22.

Para Bourdieu ${ }^{23}$ os ritos de passagem deveriam ser chamados rituais de legitimação, no sentido de que servem para a construção de alguém. O que é mais relevante no ritual da tucandeira é garantir a reprodução e a ordem social da etnia.

O desenvolvimento do corpo através do ritual é relevante nas crenças das sociedades amazônicas ${ }^{24}$. A abstenção de alimentos está associada ao princípio de conduzir o corpo à resistência. A formiga tucandeira é o distintivo diacrítico imunizante que prepara o guerreiro para as batalhas da vida adulta. Os Sateré-Mawé acreditam que após o rito os homens se tornam mais fortes, mais resistentes não só no aspecto físico, mas também no psicológico.

A família é uma micro aldeia, se o homem está pronto para liderar uma família, ele pode comandar uma aldeia. Mas se ele não tem capacidade de defender uma família, jamais defenderá sua aldeia. Esta visão de família é o princípio da organização sociopolítica da comunidade. A preocupação é com a formação do novo homem da sociedade mawé é, o qual deve estar pronto para representá-la politicamente. É neste momento de separação do jovem que a aldeia aciona a escola, os idosos, os xamãs e os outros líderes para dar orientação ao rapaz rumo ao seu desenvolvimento. Este é o âmbito pedagógico do rito da Tucandeira.

\section{CONSIDERAÇÕES FINAIS}

O ritual da Tucandeira encarna um aprendizado repassado de geração a geração por meio da tradição oral. Este conjunto de patrimônios imateriais herdado dos ascendentes sateré guardam acontecimentos históricos que marcaram a cosmovisão étnica. O seja, a dança, o cântico da tucandeira, a luva tecida com palha da floresta, o menino trazido ao

\footnotetext{
${ }^{22}$ BAHIA, Ricardo, J.B. Tragédia e esclarecimento: do crepúsculo dos deuses aos deuses do crepúsculo. In: ALVES JUNIOR, Douglas Garcia (org). Os destinos do trágico: arte, vida, pensamento. Belo Horizonte: Autêntica/ FUMEC, 2007, p. 77.

${ }^{23}$ BOURDIEU, Pierre. A miséria do mundo. Tradução de Mateus S. Soares Azevedo et. al. Petrópolis: Vozes, 2003, p.19.

${ }^{24}$ SEEGER, A.; DA MATTA, R. \& VIVEIROS DE CASTRO, E. A construção da pessoa nas sociedades indígenas brasileiras. In Pacheco de Oliveira Filho (org.). Sociedades indígenas e indigenismo no Brasil. Rio de Janeiro: Marco Zero, 1987, p.82.
}

Revista Pax Domini | Faculdade Boas Novas | v. 2 | p. 111 - 121 | mar. 2017 
ritual pelas mãos de mulheres e tantos outros elementos simbólicos presentes neste ritual de passagem, remetem à celebração de um feito mitológico da memória ancestral da etnia.

A formiga tucandeira encarna distintos símbolos culturais. Enquanto instrumento de imunização do corpo a formiga é a ferramenta utilizada como medicina para dar resistência física e psicológica ao novo guerreiro. Enquanto ferramenta de aprovação, juntamente com a luva, a formiga forma o conjunto de saberes cuja missão é de imprimir coragem e aptidão para o trabalho ao novo adulto que se forma. A capacidade de resistência à dor é a grande virtude que o rapaz Sateré deve demonstrar nesta prova. Ele não pode chorar porque o choro é sinal de fraqueza e frouxidão.

A tucandeira é o cânone feminino que confere o significado de virilidade ao jovem mawé, sendo o ato do ritual um encontro com o arquétipo do herói mítico cultural SateréMawé. É através da figura do herói Sateré que a comunidade étnica molda sua visão de mundo, ou seja, que elabora o conjunto de valores ancestrais, a autoafirmação, a busca da manutenção do patrimônio cultural e da permanência dos mitos, ritos e mistérios como permanência da própria etnia. a imunidade não é só para ter saúde no mundo concreto do indivíduo, somente para sua matéria, é também para lidar com o universo abstrato que ocupa, envolvendo a saúde da mente e da alma. O homem sateré com o fator psicológico forte pode representar e defender sua aldeia e sua família com êxito. Este despertar é o nascimento ou renascimento do jovem.

Dentro desse conjunto de invocações o ritual da Tucandeira, é marca étnica identitária que expressa crença de base espiritual. São objetos que simbolizam ritos de passagem dos Sateré-Mawé e tendem a ser descritos por narrativas que os exaltam, liricamente, como materialidade que fomentam o trabalho, o amor e a chamam vitórias em batalhas.

\section{REFERÊNCIAS}

BAHIA, Ricardo, J.B. Tragédia e esclarecimento: do crepúsculo dos deuses aos deuses do crepúsculo. In: ALVES JUNIOR, Douglas Garcia (org). Os destinos do trágico: arte, vida, pensamento. Belo Horizonte: Autêntica/ FUMEC, 2007. 
BOURDIEU, Pierre. A miséria do mundo. Tradução de Mateus S. Soares Azevedo et. al. Petrópolis: Vozes, 2003.

ELIADE, Mircea. História das crenças e ideias religiosas. Rio de Janeiro: Zahar. t.1. v.1. 1985.

Mircea. O mito do eterno retorno. Lisboa: Edições 70. 1988.

.O sagrado e o profano: a essência das religiões. São Paulo: Martins Fontes, 2001.

GUIMARÃES, Andre Eduardo. O sagrado e a historia: fenômeno religioso da historia a luz do anti-historicismo de Mircea Eliade. Porto Alegre: EDIPUCRS, 2000.

LÉVI- STRAUSS, Claude. Mito y significado. Madrid: Alianza, 1990.

LORENZ, Sônia da Silva. Sateré-mawé os filhos do guaraná. São Paulo: Centro de Trabalho Indigenista. 1992.

PEREIRA, Nunes. Os índios maués. Manaus: Ed. Valer. 1.ed., 1954. 2003.

PINHEIRO, Harold Sá Peixoto. Mitopóetica dos muyraquitãs, parandubas e moronguetás: ensaio de etonopoesia amazônica. São Paulo: Tese de Doutorado, 2013.

SEEGER, A.; DA MATTA, R. \& VIVEIROS DE CASTRO, E. A construção da pessoa nas sociedades indígenas brasileiras. In Pacheco de Oliveira Filho (org.). Sociedades indígenas e indigenismo no Brasil. Rio de Janeiro: Marco Zero, 1987.

SEGALEN, Martine. Ritos e Rituais Contemporâneos. Rio de Janeiro: FGV, 2002.

KAPFHAMMER, Wolfgang De 'sateré puro' (Sateré sese) ao 'novo sateré' (Sateré pakup): mitopráxis no movimento evangélico entre os Sateré-mawé. In: Wright, Robin (Org.). Transformando os deuses: igrejas evangélicas, pentecostais e neopentecostais entre os povos indígenas no Brasil. Campinas: Editora da Unicamp. p.101-140. 2004.

Sites

http://www.gper.com.br/noticias/e16497de60b8cdb335b018803d3040fd.pdf acessado em 10.02.2017.

https://pib.socioambiental.org/pt/povo/satere-mawe/print acessado em 05.03.2017.

http://www.terrabrasileira.com.br/indigena/ritos/640guerre.html

acessado em 04.03.2017

Revista Pax Domini | Faculdade Boas Novas | v. 2 | p. 111 - 121 | mar. 2017 